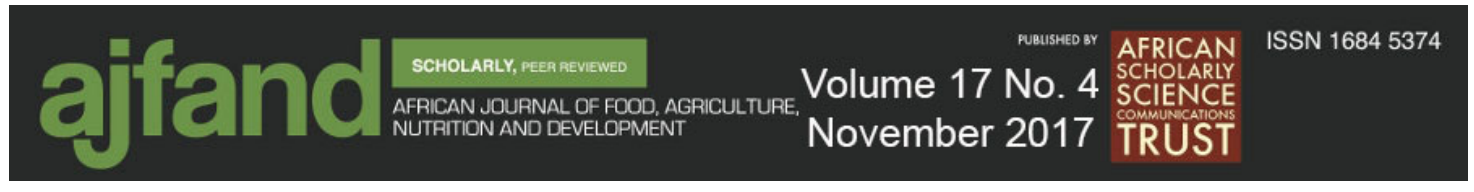

Afr. J. Food Agric. Nutr. Dev. 2017; 17(4): 12708-12721

DOI: 10.18697/ajfand.80.16880

\title{
EFFECT OF BREED AND FEEDING STRATEGY ON THE EATING QUALITY OF KENYAN BEEF
}

Wambui $\mathbf{J M}^{1^{*}}$, Karuri EG ${ }^{1}$ and PWN Kanyari ${ }^{2}$

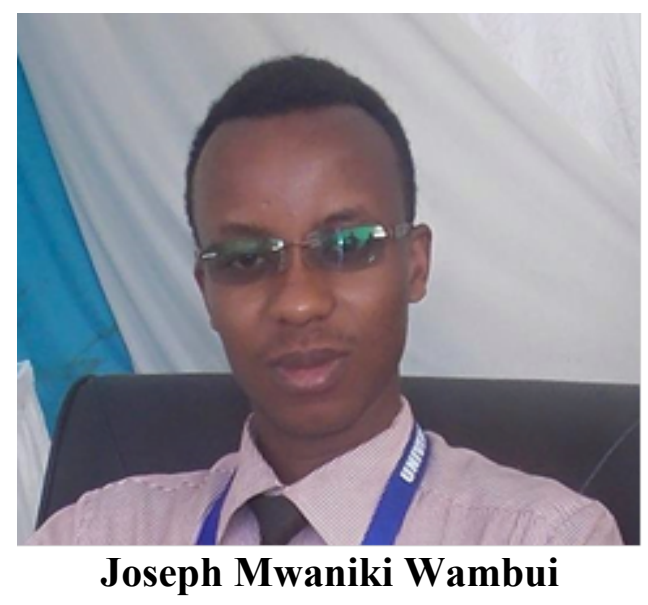

*Corresponding author's email: mwanikem@yahoo.com

${ }^{1}$ Department of Food Science, Nutrition and Technology, University of Nairobi

${ }^{2}$ Department of Veterinary Pathology, Microbiology and Parasitology, University of Nairobi 


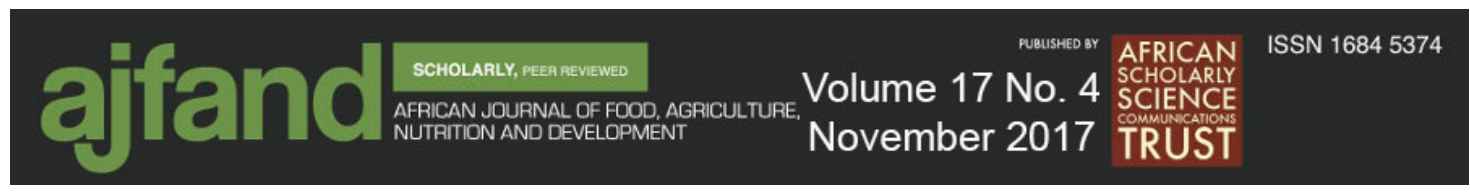

\begin{abstract}
In Kenya, most of the livestock are reared on grass using extensive pastoral systems. Nevertheless, intensive feed-lot systems to finish beef cattle have become popular among local producers. The two systems are likely to have a different impact on the eating quality of beef, because quality is determined by the combined effects of breed, nutrition and management. The effect of free-range and semi-feed lot feeding strategies on the eating quality of beef from Zebu and Sahiwal breeds was assessed. A $2 \times 2$ between subjects factorial design was used (two breeds fed using two feeding strategies). From each single breed and feeding strategy combination, seven cattle were selected after three months of feeding. The cattle were slaughtered and their rump steaks sampled. The samples were frozen for $24 \mathrm{~h}$ then thawed for $4 \mathrm{~h}$ prior to analysis. The steaks' $\mathrm{pH}$ was measured after cooking. They were then subjected to Texture Profile Analysis (TPA), 'Warner-Bratzler' Shear (WBS) tests, and organoleptic evaluations. The $\mathrm{pH}$ did not differ significantly with feeding strategy or breed $(P \geq 0.05)$. The result from TPA and WBS revealed that semi feed-lot Sahiwal beef was tender than free-range Sahiwal beef $(P<0.05)$. On the other hand, there was no difference in tenderness between feed-lot and free-range Zebu beef $(P \geq 0.05)$. An analysis between the breeds showed that feed-lot Sahiwal beef was tender than feed-lot Zebu beef $(P<0.05)$, but there was no difference in tenderness between beef from free-range Sahiwal and free-range Zebu $(P \geq 0.05)$. In the sensory analysis, there was a significant difference for each of the sensory parameters $(P<0.05$, each). Steaks from semi-feed lot Sahiwal were preferred to the other beef steaks. In conclusion, a semi-feed lot feeding strategy has the potential to improve the eating quality of beef from Sahiwal breed. Nevertheless, the improvement in the eating quality observed with Zebu breed, although not statistically significant, gives an opportunity for value chain actors to explore other management systems that can be combined with those assessed in this study to improve eating quality.
\end{abstract}

Key words: Beef, rump steak, eating quality, Sahiwal, Zebu, feed lot, pastoral, Kenya. 


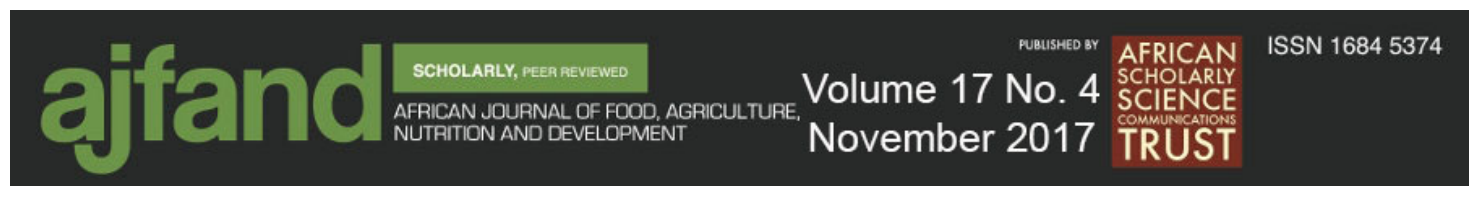

\section{INTRODUCTION}

In the fresh beef market, consumers' demand for higher quality and the drive to differentiate beef based on sensory, processing characteristics and other qualities have intensified [1]. Consequently, the meat industry in collaboration with the research community has developed new strategies to address these needs. One such strategy is the development of consumer driven feeding strategies. A feeding strategy refers to a management factor used as a quality control tool in the production of meat, mostly based on passive effects of uptake and incorporation of specific feeding components on meat quality [2]. Other important qualities include nutritional value, technological quality and shelf life [3-5], all which are desired by the modern consumer.

By definition, meat quality is a generic term that describes properties and perceptions of meat such as carcass composition and conformation, and the eating quality of meat [2]. The critical point for meat quality appraisal occurs when the product is consumed and it is this outcome that determines the decision to repurchase [6, 7]. Therefore, when evaluating meat quality, the most important elements to consider are tenderness, juiciness, and flavour [8]. Amongst these, tenderness is the dominant palatability attribute that determines meat acceptability [9]. Variability in tenderness is the main source of consumer complaint and the primary cause of failure to repurchase $[10,11]$.

Beef from a specific production system represents the combined effects of breed, nutrition and management, amongst other factors [12]. In Kenya, most of the livestock are reared on grass in extensive pastoral systems. Drought often plagues these systems, making feed less available and thus leading to meat of poor quality. Less feed intake is likely to result in less fat deposits in the muscle. Muir et al. [13] stated that there is a clear positive correlation between meat tenderness and carcass fatness. Even in periods where there is no drought, cattle fed on grass have been shown to have less weight and sensory panelist acceptability than feed-lot fed cattle [14]. The low quality of beef from the grass-fed systems may, therefore, result in sub-optimal performance of the beef industry in Kenya. Feed-lot systems to finish beef cattle from grass-based systems have received attention from some beef producers in Kenya. This may allow animals and their producers to produce beef with improved meat quality that not only meets domestic requirements but may also increase opportunities for export.

According to Muchenje et al. [15], breed and feeding management influence the quality of meat. Nevertheless, information comparing the combined effects of these factors in Kenya on the beef value chain is lacking. The objective of this study was, therefore, to assess the influence of free-range and semi-feed lot feeding strategies on the eating quality of beef from Zebu and Sahiwal breeds. Relationships among meat quality parameters in the beef were also estimated. The study, therefore, provides information for animals and beef producers about the best feeding strategy that ensures improved beef eating quality. 


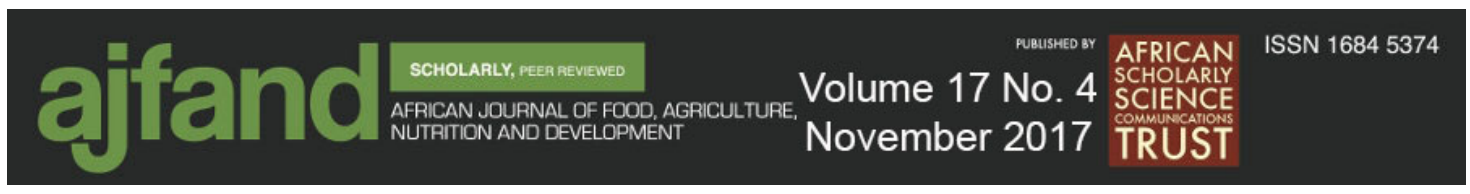

\section{MATERIALS AND METHODS}

\section{Experimental cattle}

Cattle used in this study were stratified into four mutually exclusive strata based on breed and feeding strategy. The starting age of the cattle, which was obtained from the cattle owners, was about two years. The cattle were sourced from Garissa Market in fair to poor condition due to the effects of drought. The number bought from the market was 60 (30 Sahiwal and 30 Zebus). Each of the two breeds, Zebu and Sahiwal, were divided into two feeding strategies; free range and semi-feed lot. Free-range cattle were allowed to feed exclusively on grass, while semi-feed lot cattle were fed on grass during the day and then given supplements in the evening. The supplement consisted of beef meal $(2 \mathrm{~kg})$ and hay $(1.5 \mathrm{~kg})$ per day per animal. All cattle were ranched on the Mgeno Ranch, Taita Taveta County. After the end of the feeding period (90 days), all cattle were transported for slaughter at Kenya Meat Commission (KMC), Machakos County. The cattle were trucked in two batches with semi-trailers for a distance of $420 \mathrm{Km}$ without any stops. These batches were not separated by experimental groups. The slaughter process was carried out in hygienic and sanitary conditions. Each carcass was graded using the established national standards. Carcass grading in Kenya depends on carcass weights, conformation and other quality parameters such as bruising [16]. Carcasses are graded into five classes; Classes 1 and 2 are carcasses with a well distributed white fat cover, Class 3 have poor fat distribution and lower fat cover than the stipulated Class 1 and 2, while Classes 4 and 5 are carcasses with bruises and blemishes with very little fat cover. The whole carcass sides were then aged at $2^{\circ} \mathrm{C}$ for 10 days.

\section{Experimental design and sampling plan}

A $2 \times 2$ factorial (two breeds fed using two feeding strategies) arrangement with completely randomized design was used (Table 1). A sampling interval of two carcasses (the first carcass was carcass number one on a line) was used to randomly select seven carcasses from each of the four strata from which rump steaks were taken. Rump steak is the one of the prime cuts on beef carcasses. It is obtained from the hind leg of the carcass. The rump steaks samples were subjected to textural analysis (Texture Profile Analysis (TPA) and Warner Bratzler Shear (WBS) tests), organoleptic tests and $\mathrm{pH}$ measurements.

\section{Instrumental measurements}

Samples of the 28 rump steaks were transported for 2 hours in a cool box with ice packs to the University of Nairobi's Pilot Plant located in the Department of Food Science, Nutrition and Technology (Kabete). The samples were stored chilled at $4{ }^{\circ} \mathrm{C}$ for 16 hours. Each of the samples was divided into two equal proportions cut laterally to the vertebral axis towards the tail end. Samples were placed on wire-mesh trays. The samples on trays were placed in vat cooker containing boiling water. The vat was heated by steam. During boiling, the steaks were in direct contact with the water. The samples were boiled for 40 minutes.

After cooling, each of the samples was cut into $2.5 \mathrm{~cm}$ thick steaks lateral to the previously cut surface. From each of the rump steaks, six cores measuring $2 \mathrm{~cm}$ high by $2.54 \mathrm{~cm}$ diameter and three core measuring $2 \mathrm{~cm}$ high by $1.27 \mathrm{~cm}$ diameter cores were 
obtained by hand coring at room temperature $\left(21-22^{\circ} \mathrm{C}\right)$. The corer was made of stainless steel and was about $10 \mathrm{~cm}$ long. The $2 \times 2.54 \mathrm{~cm}$ cores were used for WBS tests while the $2 \times 1.27 \mathrm{~cm}$ cores were used for TPA test. Immediately after coring, cores from each of the 28 samples were packaged in separate zipper plastic bags and frozen at $-18^{\circ} \mathrm{C}$ for 24 hours awaiting instrumental measurement. Freezing was done to slow down drip loss, which may influence textual properties due to significant moisture loss of the samples.

After the 24 hours, the samples were thawed at room temperature for 4 hours. A field $\mathrm{pH}$ meter (pHep® $\mathrm{pH}$ Tester-HI98107, Hanna Instruments, Inc., Rhode Island, USA) was used to measure the $\mathrm{pH}$ of the drip from each of the thawed samples. Texture Profile Analysis was done using the TA.XT plus Texture Analyser, (Stable Micro Systems, Godalming, UK). The samples were compressed twice to $50 \%$ of their original height. A compression platen $75 \mathrm{~mm}$ diameter (SMS P/75) and a $50 \mathrm{~kg}$ load cell were used. Pretest speed was $1.5 \mathrm{~mm} / \mathrm{s}$, test speed was $1.5 \mathrm{~mm} / \mathrm{s}$, and a target distance (distance which upon being reached, the probe being used ascends to the original trigger position at the test speed) of $30 \mathrm{~mm}$ while the trigger force was $40 \mathrm{~g}$. The following parameters were determined as described by Bourne [17]: Hardness $(\mathrm{N})$, maximum force required to compress the sample. Springiness ( $\mathrm{mm}$ ), ability of the sample to recover its original form after the deforming force was removed. Cohesiveness (ratio), extent to which the sample could be deformed prior to rupture and chewiness $(\mathrm{N} \mathrm{mm})$ work to masticate the sample for swallowing. 'Warner-Bratzler' Shear (WBS) test determined the work of shearing (N s), that is, the work needed to move the blade through the sample, estimated with a Warner-Bratzler blade attached to the same texture analyser.

\section{Organoleptic tests}

Cooking of samples for taste panel was done at the KMC sensory laboratory. Eight untrained assessors-both males and females aged above 40 years-were used for sensory analysis. They had previous experience in beef sensory analysis hence an understanding of beef sensory properties. A piece of each sample (approximately $1 \mathrm{~cm}^{3}$ ) was served to the assessors. Unsalted crackers and room temperature water were also provided to clean the palate between samples [17]. A hedonic test was carried out using a non-structured 5 point-scale (Table 2) in which the assessors evaluated different attributes: tenderness, juiciness and acceptability.

\section{Statistical analysis}

Statistical analysis was done using Genstat Edition 15 (Statistics Department, Rothamsted Experimental Station, Hertfordshire, UK). Means and standard deviations were calculated for each treatment. One-way analysis of variance was done to determine the effects of feeding regimes on tenderness and texture profile of rump steaks. Statistically significant means of tenderness and texture profile $(P<0.05)$ were separated using Duncan's mean separation test. Kruskal-Wallis H test was done to determine the effects of feeding regimes on sensory properties of the steaks. Regression equations using the texture parameters predicted by the un-trained panelist sensory characteristics of beef rump steaks were then generated. Standard error of the mean was reported for both regression equations using both WBS and stepwise regression equations using TPA parameters. 


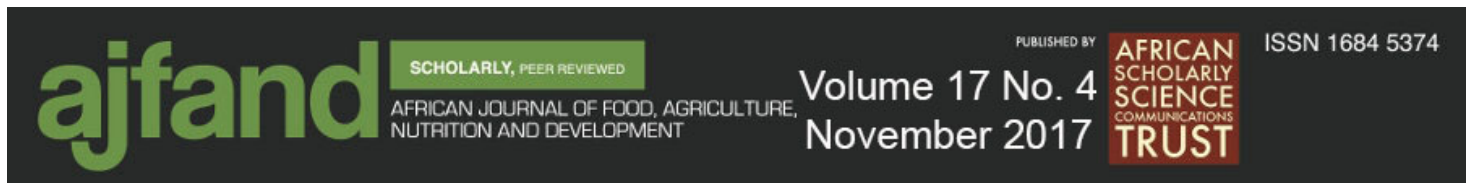

\section{RESULTS}

\section{Instrumental measurements}

In both TPA and Shear tests, the mean of shear forces and hardness increased from semifeed lot to free range in both Sahiwal and Zebu breeds (Figure 1). The two means were significantly higher in free-range than semi-feed lot Sahiwal $(P<0.05)$. Nonetheless, the two means were not significantly different in Zebu breed $(P>0.05)$. In the semi-feed lot feeding strategy, both shear forces and hardness were higher in Zebu than Sahiwal $(P<0.05)$. On the other hand, the two parameters did not differ between breeds in freerange feeding strategy $(P>0.05)$. Although the mean $\mathrm{pH}$ measurements tended to be higher in free-range feeding strategy and in both breeds as specifically in Zebu breed, no significant difference was observed in either the feeding strategy or breed $(P>0.05)$ as shown in Figure 1.

Feeding strategy and breed had no effect on springiness and cohesiveness $(P>0.05)$. On the other hand, chewiness of beef from semi-feed lot Sahiwal had significantly lower values than beef from other feeding strategies $(P<0.05)$. Table 3 summarizes the ANOVA test results for the cooked rump steaks from different feeding strategies.

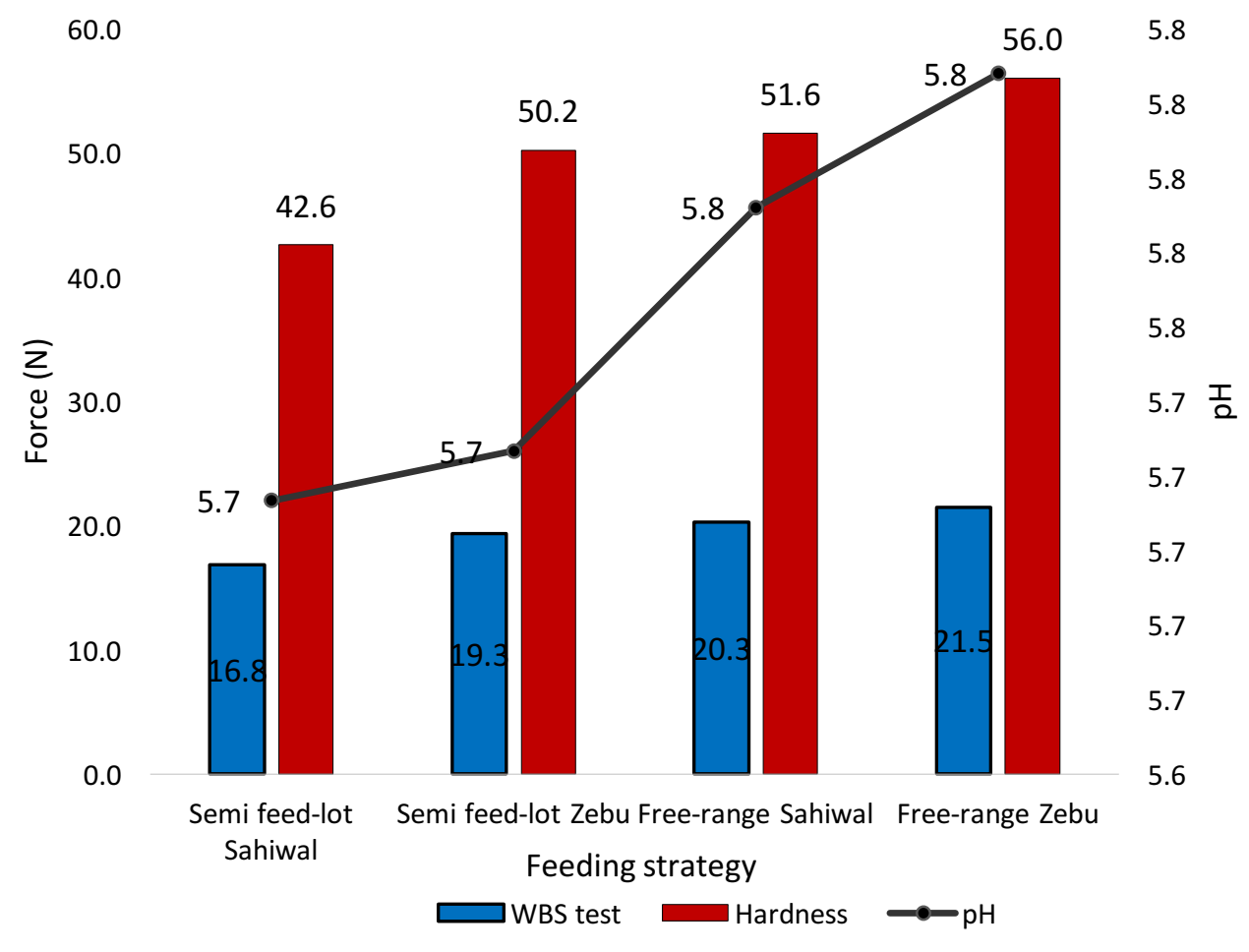

Figure 1: The Warner Bratzler Shear Test and hardness scores for Kenyan Zebu and Sahiwal breeds fed under semi-feed lot and free-range systems 
Sensory properties of sampled beef rump steaks are shown in Table 4. In all the three parameters, semi-feed lot Sahiwal had the least rank scores while free-range Zebu had the highest rank scores $(P<0.05)$.

\section{Relationship between textural and sensory measurements of beef rump steaks}

The correlations between instrumental and sensory measurements of beef rump steaks are shown in Table 5. Amongst the TPA parameters, WBS was significantly and positively correlated with hardness and springiness $(P<0.05)$. On the other hand, WBS significantly and positively correlated with juiciness and acceptability. Amongst the sensory parameters, tenderness and juiciness significantly and positively correlated with hardness, springiness and chewiness $(P<0.05)$. On the other hand, acceptability significantly and positively correlated with hardness, springiness and cohesiveness while total score significantly correlated with all the TPA parameters $(P<0.05)$.

Table 6 shows the prediction equations for sensory parameters as determined from regression equations using WBS and stepwise regression using TPA parameters. The prediction equations using WBS explained a corresponding 34\%, 31\% and $49 \%$ of the variation in tenderness, juiciness and overall palatability, respectively. On the other hand, step-wise regression analysis, which included the TPA parameter of hardness, explained $56 \%$ and $50 \%$ of the variation in initial juiciness and acceptability, respectively, while chewiness explained $52 \%$ of the initial tenderness.

Table 7 shows the prediction equations for TPA parameters as determined from regression equations using WBS. The regression equations explained a corresponding 67 and $42 \%$ of the variation in hardness and chewiness, respectively.

\section{DISCUSSION}

The semi-feed lot feeding system improved the eating quality of Sahiwal breed. This is consistent with Vestergaard et al. [19] who found out that a concentrate-based finishing period improved the meat and eating quality of the animals raised at pasture. Nevertheless, there was no improvement in the eating quality of beef from Zebu breed. According to Maltin et al. [8], nutritional strategies to improve tenderness generally attempt to increase the activation of the calpain system-proteolytic enzymes-in vivo before slaughter. Therefore, there could be differences in the system between the two breeds that may have resulted in low activation of the system in Zebu breed. In fact, the genetic influence on meat quality can occur in different breeds because of the myostatin gene in cattle [2].

Significant differences were not observed between groups for meat $\mathrm{pH}$, as was also reported by French et al. [20], Morris et al. [21] and Varela et al. [22]. Grass-fed steers had previously been reported to have a higher ultimate $\mathrm{pH}$ than grain fed steers because the later may be used to longer durations of penning and handling than the former [13]. Nevertheless, all the experimental cows used in the present study had no previous history of long duration of penning or handling. This may explain the lack of significance difference. 
In the taste panel, steak from semi-feed lot Sahiwal was the most preferred in terms of the sensory parameters tested. Two of the three tested parameters, tenderness and juiciness, are important eating quality parameters that determine consumer evaluation of meat [23], and will definitely impact on acceptability of the meat. This, like the instrumental measurements, further puts an emphasis on the influence of semi-feed lot system on Sahiwal when compared to Zebu. Nevertheless, steaks from semi-feed lot system tended to have lower tenderness scores than grass-fed system in both breeds (Table 5). This can be explained by the fact that a grass-based fattening is typically less intensive and can result in less tender meat [24].

Although consumers take into consideration many parameters when evaluating meat quality, they consider tenderness as the most important $[10,11]$. In the present study, using both regression and stepwise regression analysis to predict the relationship of sensory and textural measurements of boiled rump steaks, it was found that WBS and TPA accounted for $34 \%$ and $52 \%$ of variation in tenderness. These results are in agreement with previous studies where regression analysis of cooked beef samples had been employed. For example, Caine et al. [25] found that WBS explained 36\% of the variation in overall tenderness characteristics of cooked beef rib steaks while TPA explained $52 \%$ of the variation. On the other hand, Rhodes et al. [26] found out that instrument textural parameters accounted for about $50 \%$ of the variability for tenderness characteristics of warm roast beef. The present results further emphasize on a previous report that WBS is an imprecise predictor of beef tenderness characteristics [27]. These results are significant in that they allow the meat processors to use the most reliable analytical instruments in future. Furthermore, the effect of feed and breed in Kenyan beef animals on sensory parameters can be measured relatively easy from the instrumental measurements. This is because instruments allow for reproducibility of results unlike an untrained panelist.

\section{CONCLUSION}

A semi-feed lot feeding strategy that incorporates a combination of grass feeding during the day and concentrate feeding during the evening has the potential to improve the eating quality of beef from Sahiwal breed of the Zebu breed whose performance was higher than that of the Sahiwal breed in both feeding strategies. Nevertheless, the improvement observed, though not statistically significant gives an opportunity to explore other management systems that can be incorporated with what was tested in this study to improve the eating quality.

\section{ACKNOWLEDGEMENT}

The authors are grateful to the World Bank for financing the project through the Kenya Agricultural Productivity and Agribusiness Project, KAPAP. 


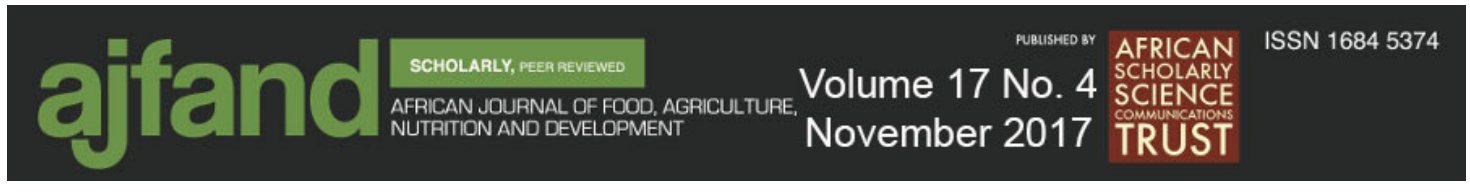

Table 1: Experimental design

\begin{tabular}{|l|l|l|}
\hline Treatment & Feeding strategy & Breed $^{\mathrm{b}}$ \\
\hline Treat1 & SF & ZB \\
\hline Treat2 & FR & ZB \\
\hline Treat3 & SF & SB \\
\hline Treat4 & FR & SB \\
\hline
\end{tabular}

${ }^{\mathrm{a}}$ Abbreviations used: $\mathrm{SF}=$ Semi-feed lot feeding strategy; $\mathrm{FR}=$ Free range feeding strategy;

${ }^{\mathrm{b}}$ Abbreviations used $\mathrm{ZB}=\mathrm{Zebu}$ breed; SB: Sahiwal breed

Table 2: A five point hedonic scale used by assessors to evaluate the effect of breed and feeding strategy on sensory properties of beef from Kenya Zebu and Sahiwal breeds

\begin{tabular}{|l|l|l|l|}
\hline Score & Tenderness & Juicy & Acceptability \\
\hline $\mathbf{1}$ & Extremely Tender & Extremely Juicy & Extremely Acceptable \\
\hline $\mathbf{2}$ & Moderately Tender & Moderately Juicy & Moderately Acceptable \\
\hline $\mathbf{3}$ & Tender & Juicy & Acceptable \\
\hline $\mathbf{4}$ & Moderately Tough & Moderately Dry & Moderately Unacceptable \\
\hline $\mathbf{5}$ & Very Tough & Very Dry & Very Unacceptable \\
\hline
\end{tabular}

Table 3: Means \pm SD and the significance $(P<0.05)$ of some of the Texture Profile Analysis (TPA) parameters of cooked rump steaks

\begin{tabular}{|l|l|l|l|}
\hline Feeding strategy/breed & $\begin{array}{l}\text { TPA parameter } \\
\text { Springiness } \\
(\mathbf{m m})\end{array}$ & $\begin{array}{l}\text { Cohesiveness } \\
\text { (ratio) }\end{array}$ & $\begin{array}{l}\text { Chewiness } \\
\text { (N mm) }\end{array}$ \\
\hline Semi feed-lot Sahiwal & $6.6 \pm 0.4^{\mathrm{a}}$ & $0.57 \pm 0.06^{\mathrm{a}}$ & $160 \pm 50^{\mathrm{a}}$ \\
\hline Semi feed-lot Zebu & $6.8 \pm 0.6^{\mathrm{a}}$ & $0.59 \pm 0.05^{\mathrm{a}}$ & $200 \pm 36^{\mathrm{b}}$ \\
\hline Free-range Sahiwal & $6.8 \pm 1.0^{\mathrm{a}}$ & $0.61 \pm 0.04^{\mathrm{a}}$ & $212 \pm 47^{\mathrm{b}}$ \\
\hline Free-range Zebu & $6.7 \pm 0.6^{\mathrm{a}}$ & $0.60 \pm 0.03^{\mathrm{a}}$ & $224 \pm 99^{\mathrm{b}}$ \\
\hline
\end{tabular}

${ }^{\mathrm{c}} \mathrm{Common}$ letters in a row represent statistically significant means 


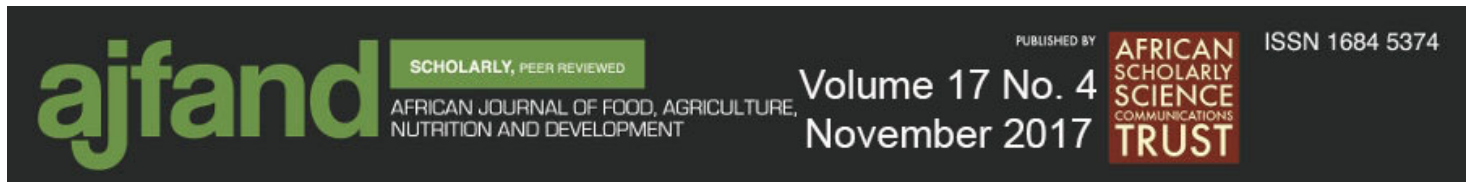

Table 4: The mean ranks of each of the sensory properties of beef rump steaks from each of the feeding strategy and breed combination using the Kruskal-Wallis H test

\begin{tabular}{|l|l|l|l|}
\hline Feeding strategy/Breed & Tenderness & Juiciness & Acceptability \\
\hline Semi feed-lot Sahiwal & 28.1 & 29.5 & 24.1 \\
\hline Semi feed-lot Zebu & 32.1 & 30.6 & 33.0 \\
\hline Free-range Sahiwal & 32.5 & 30.5 & 33.2 \\
\hline Free-range Zebu & 37.3 & 39.4 & 39.8 \\
\hline
\end{tabular}

Table 5: Correlation coefficients ( $P$ values) for Warner-Bratzler shear force (WBS) and texture profile analysis parameters with the panelists' sensory characteristics of rump steaks

\begin{tabular}{|c|c|c|c|c|c|}
\hline & \multirow[t]{2}{*}{ WBS } & \multicolumn{4}{|c|}{ Texture Profile Analysis } \\
\hline & & $\begin{array}{l}\text { Hardness } \\
\text { (N) }\end{array}$ & $\begin{array}{l}\text { Springiness } \\
(\mathrm{mm})\end{array}$ & $\begin{array}{l}\text { Cohesiveness } \\
\text { (ratio) }\end{array}$ & $\begin{array}{l}\text { Chewiness } \\
\text { (N mm) }\end{array}$ \\
\hline WBS & - & $0.857 * *$ & $0.738 * *$ & 0.000 & 0.452 \\
\hline Tenderness & 0.381 & $0.683^{*}$ & $0.244^{*}$ & 0.366 & $0.810 * *$ \\
\hline Juiciness & $0.611^{*}$ & $0.611^{*}$ & $0.563 *$ & 0.419 & $0.635^{*}$ \\
\hline Acceptability & $0.679 *$ & $0.752 * *$ & $0.570^{*}$ & $0.570^{*}$ & 0.582 \\
\hline Total Score & 0.467 & $0.719^{*}$ & $0.491^{*}$ & $0.647^{*}$ & $0.850 *$ \\
\hline
\end{tabular}

$* P<0.05 ; * * P<0.01$

WBS- Bratzler shear force

Table 6: Regression equations using Warner-Bratzler shear force (WBS) and Texture Profile Analysis (TPA) parameters to predict sensory properties of beef rump steaks

\begin{tabular}{|c|c|c|c|}
\hline Prediction equations $\mathrm{d}^{\mathrm{d}^{*}}$ & $\mathrm{R}^{2}$ & S.E.M. ${ }^{\mathrm{e}}$ & $P$ value ${ }^{\dagger}$ \\
\hline $\mathrm{TE}=1.32(0.09)+0.06(0.07) \mathrm{WBS}$ & 0.34 & 0.62 & 0.07 \\
\hline$T E=1.24(0.003)+0.07(0.001) C H$ & 0.52 & 0.46 & $<0.001$ \\
\hline$J U=1.70(0.01)+0.07(0.06) W B S$ & 0.31 & 0.46 & 0.06 \\
\hline $\mathrm{JU}=1.42(<0.001)+0.026(<0.001) \mathrm{HA}$ & 0.56 & 0.17 & $<0.001$ \\
\hline $\mathrm{AC}=1.68(<0.0010+0.04(0.04) \mathrm{WBS}$ & 0.49 & 0.33 & 0.03 \\
\hline $\mathrm{AC}=1.57(<0.001)+0.19(0.02) \mathrm{HA}$ & 0.50 & 0.31 & 0.02 \\
\hline \multicolumn{4}{|c|}{$\begin{array}{l}{ }^{\mathrm{d}} \text { Abbreviations used in the prediction equations were; TE=Tenderness; JU=Juiciness; AC=Acceptability; } \\
\text { WBS=Warner-Bratzler shear force; } \mathrm{CH}=\text { Chewiness; HA=Hardness } \\
\text { e } \mathrm{S} \text {.E.M.: standard error of the mean reported for both regression equations using both WBS and stepwise } \\
\text { regression equations using TPA parameters } \\
\text { *Numbers in parenthesis indicate significance test of the intercept and dependent variable retained in the } \\
\text { regression analysis } \\
{ }^{\dagger} \text { Significance test of the predictive model }\end{array}$} \\
\hline
\end{tabular}


Table 7: Regression equations using Warner-Bratzler shear force (WBS) to predict texture profile analysis (TPA) of beef rump steaks

\begin{tabular}{|l|l|l|l|}
\hline Prediction equation & $\mathrm{R}^{2}$ & S.E.M. ${ }^{\mathrm{g}}$ & $P_{\text {value }}$ \\
\hline $\mathbf{H A}=\mathbf{9 . 7 2}(\mathbf{0 . 1 3})+\mathbf{2 . 1 0}(<\mathbf{0 . 0 0 1}) \mathbf{W B S}$ & 0.67 & 16.46 & $<0.001$ \\
\hline $\mathbf{S P}=\mathbf{7 . 4 7}(<\mathbf{0 . 0 0 1})+\mathbf{0 . 0 4}(\mathbf{0 . 0 8}) \mathbf{W B S}$ & 0.11 & 1.18 & 0.08 \\
\hline $\mathbf{C O}=\mathbf{0 . 5 9}(<\mathbf{0 . 0 0 1})+\mathbf{0 . 0 0 1}(\mathbf{0 . 7 0}) \mathbf{W B S}$ & 0.01 & 0.07 & 0.69 \\
\hline $\mathbf{C H}=\mathbf{6 3 . 1}(\mathbf{0 . 8 1})+\mathbf{7 . 1 7}(<\mathbf{0 . 0 0 1}) \mathbf{W B S}$ & 0.42 & 92.14 & $<0.001$ \\
\hline
\end{tabular}

${ }^{\mathrm{f}} \mathrm{Abbreviations} \mathrm{used} \mathrm{in} \mathrm{the} \mathrm{prediction} \mathrm{equations} \mathrm{were;} \mathrm{HA}=$ Hardness; $\mathrm{SP}=$ Springiness; $\mathrm{CO}=$ Cohesiveness; $\mathrm{CH}=$ Chewiness; $\mathrm{WBS}=$ Warner-Bratzler shear force

${ }^{\mathrm{g}}$ Standard error of the mean reported for regression equations using WBS

*Numbers in parenthesis indicate significance test of the intercept and dependent variable retained in the regression analysis

${ }^{\dagger}$ Significance test of the predictive model 


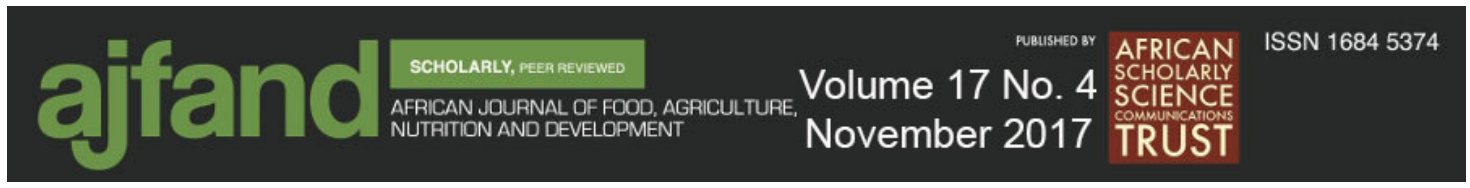

\section{REFERENCES}

1. Scollan N, Hocquette JF, Nuernberg K, Dannenberger D, Richardson I and A Moloney Innovations in beef production systems that enhance the nutritional and health value of beef lipids and their relationship with meat quality. Meat Science, 2006; 74(1): 17-33.

2. Andersen HJ, Oksbjerg N, Young JF and M Therkildsen Feeding and meat quality - a future approach. Meat Science, 2005; 70: 543-554.

3. Granit R, Angel S, Akiri B, Holzer Z, Aharoni Y, Orlov A and J Kanner Effects of vitamin E supplementation on lipid peroxidation and color retention of salted calf muscle from a diet rich in polyunsaturated fatty acids. Journal of Agricultural and Food Chemistry, 2001; 49(12): 5951-5956.

4. Sheard P, Enser M, Wood J, Nute G, Gill B and R Richardson Shelf life and quality of pork and pork products with raised n-3 PUFA. Meat Science, 2000; 55(2): 213-221.

5. Wood JD, Richardson RI, Nute GR, Fisher AV, Campo MM, Kasapidou E, Sheard PR and M Enser Effects of fatty acids on meat quality: a review. Meat Science, 2004; 66(1):21-32.

6. Boleman SJ, Boleman SL, Miller RK, Taylor JF, Cross HR, Wheeler TL, Koohmaraie M, Shackelford SD, Miller MF, West RL, Johnson DD and JW Savell Consumer evaluation of beef of known categories of tenderness. Journal of Animal Science, 1997; 75(6): 1521-1524.

7. Verbeke $\mathbf{W}$ and $\mathbf{J}$ Viaene Beliefs, attitude and behaviour towards fresh meat consumption in Belgium: empirical evidence from a consumer survey. Food Quality and Preference, 1999; 10(6): 437-445.

8. Maltin C, Balcerzak D, Tilley $\mathbf{R}$ and $M$ Delday Determinants of meat quality: tenderness. The Proceedings of the Nutrition Society, 2003; 62(2): 337-347.

9. Crouse JD, Cundiff LV, Koch RM, Koohmaraie M and SC Seideman Comparisons of Bos indicus and Bos taurus inheritance for carcass beef characteristics and meat palatability. Roman L. Hruska U.S. Meat Animal Research Center: Paper 121; 1993.

http://digitalcommons.unl.edu/hruskareports/121 Accessed January 15, 2016.

10. Tarrant PV Some recent advances and future priorities in research for the meat industry. Meat Science, 1998; 49: S1-S16.

11. Bindon $\mathbf{B}$ and $\mathbf{N}$ Jones Cattle supply, production systems and markets for Australian beef. Australian Journal of Experimental Agriculture, 2001; 41: 861877. 


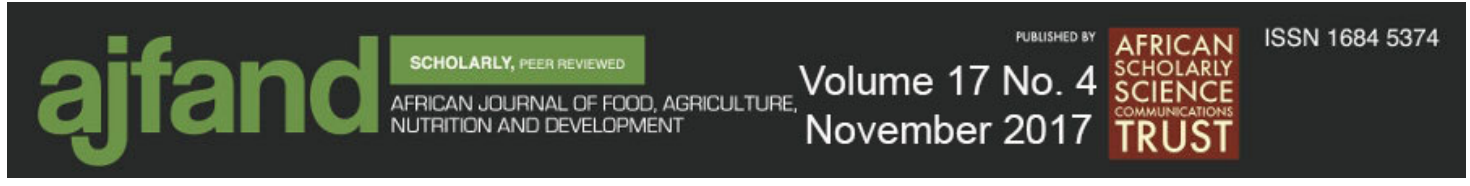

12. Raes K, Balcaen A, Dirinck P, De Winne A, Claeys E, Demeyer D and S De Smet Meat quality, fatty acid composition and flavour analysis in Belgian retail beef. Meat Science, 2003; 65(4): 1237-1246.

13. Muir PD, Deaker JM and MD Bown Effects of forage- and grain-based feeding systems on beef quality: A review. New Zealand Journal of Agricultural Research, 1998; 41(4): 623-635.

14. Muir PD, Smith NB, Wallace GJ, Cruickshank GJ and DR Smith The effect of short-term grain feeding on liveweight gain and beef quality. New Zealand Journal of Agricultural Research, 1998; 41(4): 517-526.

15. Muchenje V, Dzama K, Chimonyo M, Raats JG and PE Strydom Meat quality of Nguni, Bonsmara and Aberdeen Angus steers raised on natural pasture in the Eastern Cape, South Africa. Meat Science, 2008; 79(1): 20 -28.

16. Farmer $\mathbf{E}$ and $\mathbf{J}$ Mbwika End market analysis of Kenyan livestock and meat: A desk study: The Accelerated Microenterprise Advancement Project (AMAP) Knowledge and Practice, micro-report \#184. Nairobi: USAID, 2012. http://www.microlinks.org/sites/microlinks/files/resource/files/Kenya Livestoc k_End Market_Study.pdf Accessed January 12, 2016.

17. Bourne M Food Texture and Viscosity: Concept and Measurement. Waltham, Massachusetts, USA: Academic Press, 2002.

18. Calvo MM, García ML and MD Selgas Dry fermented sausages enriched with lycopene from tomato peel. Meat Science, 2008; 80(2): 167-172.

19. Vestergaard M, Oksbjerg $\mathbf{N}$ and $\mathbf{P}$ Henckel Influence of feeding intensity, grazing and finishing feeding on muscle fibre characteristics and meat colour of semitendinosus, longissimus dorsi and supraspinatus muscles of young bulls. Meat Science, 2000; 54(2): 177-185.

20. French P, O’Riordan EG, Monahan FJ, Caffrey PJ, Vidal M, Mooney MT, Troy DJ and AP Moloney Meat quality of steers finished on autumn grass, grass silage or concentrate-based diets. Meat Science, 2000; 56(2): 173-80.

21. Morris ST, Purchas RW and DL Burnham Short-term grain feeding and its effect on carcass and meat quality. Proceedings of the New Zealand Society of Animal Production, 1997; 57: 275-277.

22. Varela A, Oliete B, Moreno T, Portela C, Monserrrat L, Carballo JA and L Sanchez Effect of pasture finishing on the meat characteristics and intramuscular fatty acid profile of steers of the Rubia Gallega breed. Meat Science, 2004; 67(3): $515-522$.

23. Maltin C, Balcerzak D, Tilley $\mathbf{R}$ and $\mathbf{M}$ Delday Determinants of meat quality: tenderness. The Proceedings of the Nutrition Society, 2003; 62: 337-347. 


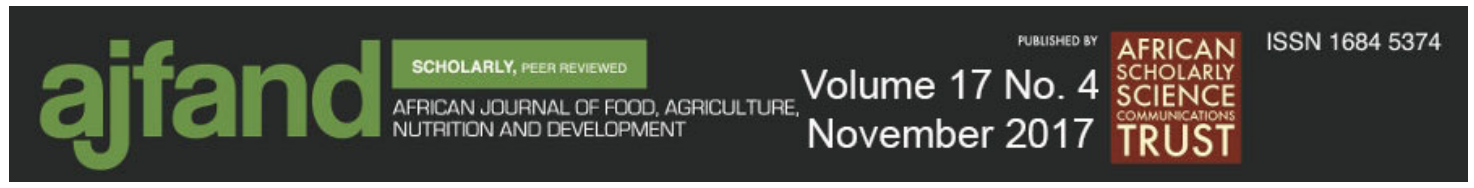

24. Mitchell GE, Reed AW and SA Rogers Influence of feeding regimen on the sensory qualities and fatty acid contents of beef steaks. Journal of Food Science, 1991; 56(4): 1102-1103.

25. Caine WR, Aalhus JL, Best DR, Dugan MER and LE Jeremiah Relationship of texture profile analysis and Warner-Bratzler shear force with sensory characteristics of beef rib steaks. Meat Science, 2003; 64(4): 333-339.

26. Rhodes DN, Jones RCD, Chrystall BB and JM Harries Meat texture: II. The relationship between subjective assessments and a compressive test on roast beef. Journal of Texture Studies, 1972; 3(3): 298-309.

27. Shackelford SD, Wheeler TL and M Koohmaraie Tenderness classification of beef: I. Evaluation of beef longissimus shear force at 1 or 2 days postmortem as a predictor of aged beef tenderness. Journal of Animal Science, 1997; 75(9): 2417-2422. 